\title{
Physical properties and lung deposition of particles emitted from five major indoor sources
}

\author{
Tuan V. Vu ${ }^{1}$ - Jakub Ondracek ${ }^{2}$ - Vladimir Zdímal ${ }^{2}$. Jaroslav Schwarz ${ }^{2}$. \\ Juana Maria Delgado-Saborit ${ }^{1}$ - Roy M. Harrison ${ }^{1,3}$
}

Received: 8 March 2016 / Accepted: 25 July 2016/Published online: 25 August 2016

(C) The Author(s) 2016. This article is published with open access at Springerlink.com

\begin{abstract}
The physical properties of indoor particles were measured with an Scanning Mobility Particle Sizer (SMPS) system (14.6-850 nm), an Aerodynamic Particle Sizer (APS, 0.54-18 $\mu \mathrm{m})$ and an Hygroscopic Tandem Differential Mobility Analyzer (H-TDMA) in an apartment located in an urban background site in Prague (Czech Republic) from 15 August to 8 September, 2014. The total particle maximum number concentration was $9.38 \times 10^{4}, 1.46 \times 10^{5}, 2.89 \times 10^{4}$, $2.25 \times 10^{5}$ and $1.57 \times 10^{6}$ particles $\mathrm{cm}^{-3}$ for particles released from vacuum cleaning, soap/W5 cleaning spray, smoking, incense burning and cooking (frying) activities, respectively. Particles emitted from cleaning activities showed unimodal number size distributions, with the majority of particles $(>98.2 \%)$ in the ultrafine size range $(\mathrm{Dp}<100 \mathrm{~nm})$ and modes at a diameter of $19.8 \mathrm{~nm}$ for vacuum cleaning and $30.6 \mathrm{~nm}$ for soap/W5 cleaning. Smoking and incense burning
\end{abstract}

Highlights

- Particle size distribution and effective density from five major indoor sources

- Hygroscopic properties of indoor particles in the regions of the lung

- Regional lung deposition fraction of indoor particles using a modified MDDP model

- Comparison of regional lung dose of particles emitted from different indoor sources

Roy M. Harrison

r.m.harrison@bham.ac.uk

1 Division of Environmental Health \& Risk Management, School of Geography, Earth \& Environmental Sciences, University of Birmingham, Edgbaston, Birmingham B15 2TT, UK

2 Institute of Chemical Process Fundamentals of the ASCR (ICPF), Prague 165 02, Czech Republic

3 Department of Environmental Sciences/Center of Excellence in Environmental Studies, King Abdulaziz University, PO Box 80203, Jeddah 21589, Saudi Arabia predominantly generated particles in the accumulation mode with a count median diameter around $90-150 \mathrm{~nm}$ while cooking emissions showed a bimodal structure with a main mode at $47.8 \mathrm{~nm}$. Particles from vacuum cleaning, incense burning, smoking and cooking emissions were found to be "nearly hydrophobic" with an average growth factor $\left(\mathrm{G}_{\mathrm{f}}\right)$ around 1.01-1.10, while particles emitted from desk cleaning using organic compounds were found to be "lesshygroscopic" $\left(\mathrm{G}_{\mathrm{f}} \sim 1.12-1.16\right)$. Based on an adjusted MPPD model with a consideration of the hygroscopic properties of particles, the total lung deposition fractions of these particles by number when they penetrate into the human lung were $0.73 \pm 0.02,0.62 \pm 0.03,0.37 \pm 0.03,0.32 \pm 0.03$ and $0.49 \pm$ 0.02 for vacuum cleaning, desk cleaning, smoking, incense burning and cooking, respectively.

Keywords Indoor sources $\cdot$ Particle size $\cdot$ Hygroscopic growth $\cdot$ Lung deposition

\section{Introduction}

People in developed countries spend the majority of their time (approximately $90 \%$ ) in indoor environments (DelgadoSaborit et al. 2011), and as consequence they may be exposed to a range of pollutants of an indoor origin, particularly ultrafine particles which may cause cardiovascular, respiratory, and neurological hazards to human health (Diffey 2011; Donaldson et al. 1998). Morawska et al. (2013) reported that $19-76 \%$ of the integrated daily residential exposure to ultrafine particles originated from indoor-generated particles.

In recent years, many studies have been performed to characterize a range of indoor-generated particles from various microenvironments such as home, office, school or work place. For example, He et al. (2004) measured the contribution 
from 21 different types of indoor activities to particle number and mass concentration in 15 residential houses. Their study found that the indoor particle number concentrations showed an increase by 1.5 to over 27 times during the indoor activities, while the $\mathrm{PM}_{2.5}$ concentration was also estimated to increase during smoking, grilling and frying activities from 3 to 90 times above the background level. Similarly, Bhangar et al. (2011) investigated ultrafine particle concentration in seven residences in northern California and indicated that cooking was the most important indoor activity contributing to the indoor ultrafine particle level.

Different types of indoor activities release particles with different physical properties including their size distribution. The majority of particles generated from indoor combustion sources including cooking, wood burning, candle burning, fireplace or kerosene heating were found in the submicron size range (Hussein et al. 2006). On the other hand, particles originating from resuspension from indoor surfaces due to building occupant movement are predominantly distributed in the coarse mode, with a diameter lager than $1 \mu \mathrm{m}$ (Thatcher and Layton 1995). Characterization of the particle size distribution of indoor sources is not only useful in determining the regional lung deposition of particles, but also in source apportionment of indoor aerosols based on receptor modelling methods $\mathrm{Cu}$ et al. 2015b). Ogulei et al. (2006) ran a positive matrix factorization (PMF) analysis on indoor particle size distributions in an occupied townhouse in Reston (Washington, DC, USA) to identify the contribution of indoor sources to indoor aerosols.

Although the number of studies focusing on indoor aerosols has increased in recent years, the physical characterization database of indoor sources, particularly the hygro scopicity of indoor particles which is known to be an important determinant of lung deposition fraction of particles in the human respiratory tract, is still limited (Vu et al. 2015a). The aim of this study was to investigate physical properties including size distribution, effective density and hygroscopicity of particles originating from five typical indoor sources. The regional lung deposition fraction of indoor particles was calculated based on a modified Multiple-Path Particle Dosimetry Model (MPPD). Finally, the minute regional lung dose of indoor-generated particles was estimated and compared.

\section{Materials and methods}

\section{Site description and data measurement}

The experimental campaign was conducted from 15 August to 8 September, 2014 in an apartment located in the suburban background of Prague, Czech Republic. The apartment was unoccupied during the sampling period. It is located on the ground floor of a two-floor building and has a living room, a small bathroom next to the kitchen and two bedrooms, one of them containing the instruments. The apartment (as shown in Fig. 1) and sampling site have been described in detail by Hussein et al. (2006).

The particle number size distribution (14.6-850 nm) was measured by a Scanning Mobility Particle Sizer system (SMPS 3696, TSI Inc., USA) comprising a TSI 3080 electrostatic classifier, a TSI 3081 differential mobility analyzer (long DMA) and a TSI 3775 condensation particle counter (CPC). Larger particles and their number size distribution $(0.54$

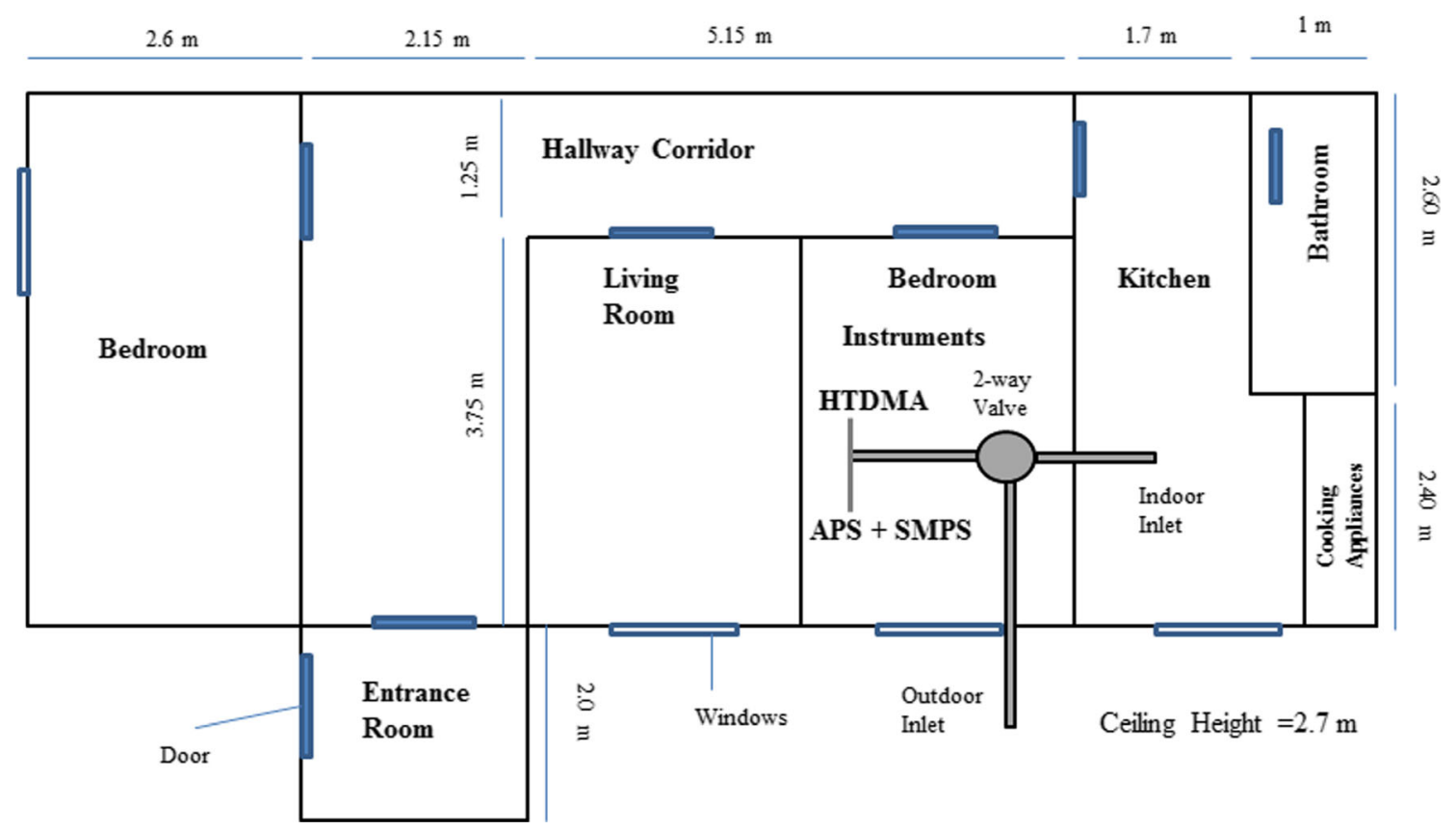

Fig. 1 Plan view of the apartment 
$18 \mu \mathrm{m}$ ) were measured by an Aerodynamic Particle Sizer (APS 3321, TSI Inc., USA). The SMPS system was operated at low aerosol flow rate of $0.3 \mathrm{~L} \mathrm{~min}^{-1}$ and the APS flow rate was $5 \mathrm{~L} \mathrm{~min}^{-1}$, with 5 min time resolution. A Hygroscopic Tandem Differential Mobility Analyzer (HTDMA) developed by the Laboratory of Aerosol Chemistry and Physics, Institute of Chemical Process Fundamentals of the ASCR (ICPF, Czech Republic) was installed to measure the hygroscopic growth factors at $90 \%$ relative humidity for particles with three selected initial dry sizes at diameters of 50, 100 and $200 \mathrm{~nm}$.

Indoor particles were generated in a closed kitchen, whose dimensions are shown in Fig. 1. The cleaning, smoking, incense burning and cooking activities were conducted during a period of approximately 10, 5, 60 and $20 \mathrm{~min}$, respectively. Smoking experiments were conducted by two persons who smoked with two cigarettes inside the kitchen. Cooking particles were generated by frying sausages with sunflower oil, and toasting bread. The indoor concentration was at a background level before generating indoor sources. The sampling inlet was put in the breathing zone. All SMPS/APS datasets were corrected for particle loss inside the inlet tube before data analysis.

\section{Data handling}

\section{Merging SMPS/APS data}

Two types of data sets (aerodynamic and mobility) collected from APS and SMPS instruments were merged into one particle size spectrum matrix (mobility diameter from 0.015 to $10 \mu \mathrm{m}$ ) using an enhanced algorithm which was developed in CRAN R by Beddows et al. (2010). The effective density of particles was estimated based on the best fit between two instrument (APS/SMPS) datasets for number, surface area and volume spectra. The final diameter type obtained by this enhanced merging algorithm was mobility diameter. This type of diameter may be converted to aerodynamic diameter using the following equation:

$\mathrm{D}_{\mathrm{a}}=\mathrm{x} \cdot \mathrm{D}_{\mathrm{m}} \cdot \sqrt{\frac{\mathrm{C}\left(\mathrm{D}_{\mathrm{m}}\right)}{\mathrm{C}\left(\mathrm{D}_{\mathrm{a}}\right)}}$

$\mathrm{x}=\sqrt{\frac{\rho_{e}}{\rho_{o}}}$

where, $D_{\mathrm{a}}, D_{\mathrm{m}}$ are aerodynamic and mobility diameters (nm), respectively, $C$ is the Cunningham slip correction factor and $x$ is known as the free parameter that is determined by giving the best fit between APS/SMPS spectra. $\rho_{0}$ is unit density and $\rho_{\mathrm{e}}$ is the estimated transition-regime effective density $\left(\mathrm{g} \mathrm{cm}^{-3}\right)$. PM mass concentrations were estimated from the merged size distribution and effective density. In this study, we assume particles are spherical; therefore, their mobility diameters are equal to their equivalent volume diameter. Mobility diameter was used as the input diameter in the MPPD model.

\section{Estimation of hygroscopic growth factors in regions} of the lung

To analyse the growth factors from the HTDMA, a TDMAinv conversion approach provided by the Laboratory of Atmospheric Chemistry, Paul Scherrer Institute (PSI, Switzerland) was applied (Gysel et al. 2009). This TDMAinv toolkit was run on the Igor Wave Metric software version 6.1. This algorithm retrieved the actual growth factor probability density function $\left(\mathrm{G}_{\mathrm{f}}-\mathrm{PDF}\right)$ as a piecewise linear function from the measurement distribution function of the HTDMA. The $\mathrm{G}_{\mathrm{f}}-\mathrm{PDF}$ is defined as the growth factor probability density function, $c(g, D)$, for particles with dry diameter $D=D_{0}$ to present a growth factor $\left(\mathrm{G}_{\mathrm{f}}\right)=g$, and the total probability of the presented $\mathrm{G}_{\mathrm{f}}$ is unity: $\int_{0}^{\infty} c\left(g, D_{0}\right) d g=1$ (Gysel et al. 2009). In this study, the HTDMA measured the mean growth factor at $90 \% \mathrm{RH}: \mathrm{G}_{\mathrm{f} \text { mean }}=\int_{0}^{\infty} g c\left(g, D_{0}\right) d g$.

To calculate the growth factors at $99.5 \% \mathrm{RH}$, which is assumed for the RH in the respiratory tract, from the observed growth factor at $90 \% \mathrm{RH}$ from our TDMA measurements, we applied an approach provided by Rissler et al. (2010) using the following calculation:

$\mathrm{G}_{\mathrm{f}-99.5 \%}=\sqrt[3]{1+\frac{99.5}{90}\left(G_{f-90 \%}^{3}-1\right) \frac{\left(C_{k} \text { at } 90 \% R H^{-0.90)}\right.}{\left(C_{k} \text { at } 99.5 \% R H^{-0.95)}\right.}}$

where $C_{\mathrm{k}}$ is the Kelvin curvature correction factor:

$C_{\mathrm{k}}$ at $\quad a \% \quad R H=\exp \left(\frac{4 \mathrm{M}_{\mathrm{W}} \sigma_{\mathrm{s}}}{\text { RT. } \rho_{\mathrm{w}} \mathrm{D}_{\mathrm{p}-\mathrm{at}} \mathrm{a} \% \mathrm{RH}}\right)$

$M_{\mathrm{W}}\left(18 \mathrm{~g} \mathrm{~mol}^{-1}\right)$ and $\rho_{\mathrm{w}}\left(1 \mathrm{~g} \mathrm{~cm}^{-3}\right)$ are the molecular weight and density of water; $\sigma_{\mathrm{s}}$ is the surface tension of the solution (assuming a surface tension of $0.072 \mathrm{~J} \mathrm{~m}^{-2}$ ); $R$ ( $\left.8.314 \mathrm{~J} \mathrm{~mol}^{-1}\right)$ and $T(298 \mathrm{~K})$ are the ideal gas constant and temperature, respectively, and $D_{\mathrm{p}}$ is the particle diameter (nm).

In this study, the HTMA only measured particles at three selected dry sizes of 50, 100 and $200 \mathrm{~nm}$ at $90 \%$ RH. For particles of below $50 \mathrm{~nm}$ and over $200 \mathrm{~nm}$, this study assumed that the soluble volume fraction of particles at a diameter of $50 \mathrm{~nm}$ is also descriptive of those smaller than $50 \mathrm{~nm}$ while those of particles with a diameter of $200 \mathrm{~nm}$ also describe those larger than $200 \mathrm{~nm}$. In our measurements, particle size distributions were collected using SMPS/APS instruments without a dryer. It is therefore necessary to calculate the effects of ambient humidity on the size distribution measured by the SMPS/APS before using the data for the lung dose calculation. The dry diameter of a particle can be estimated by the ratio of particle size measured by SMPS and the growth factor of that dry 
particle in the ambient relative humidity $(\mathrm{RH})$. The $\mathrm{RH}$ for the indoor environment during vacuum cleaning, soap cleaning, smoking, incense burning and cooking was 47.9, 57.2, 47.3, 66.21 and $72.8 \%$, respectively. According to our calculation, the effect of ambient relative humidity on the measured size distributions is not significant since the growth factors of particles were approximately unity under these low RH conditions.

When a particle penetrates into the lung, its growth not only depends on particle size but also upon its residence time. To address the particle growth dependence upon time, we used an approach provided by Ferron (1977):

$$
\mathrm{F}(\mathrm{t})=\frac{\mathrm{Dp}(\mathrm{t})-\mathrm{Dp}(0)}{\mathrm{Dp}(\mathrm{e})-\mathrm{Dp}(0)}=\frac{\operatorname{Dp}(0) \times\left[\exp \left(-\frac{10 \mathrm{t}^{0.55}}{\mathrm{Dp}(0)}\right)^{0.6}-1\right]}{\mathrm{Dp}(\mathrm{e})-\operatorname{Dp}(0)}
$$

where $F(t)$ is fraction of particles at equilibrium size, $\mathrm{Dp}(t)$ is particle diameter at time $t(\mathrm{~s}) ; \mathrm{Dp}(0)$ is the initial dry particle diameter $(\mu \mathrm{m}), \mathrm{Dp}(\mathrm{e})$ is equilibrium particle diameter $(\mu \mathrm{m})$ and $t$ in the residence time in the lung(s).

Therefore, the particle growth factor in each region will be calculated by:

Averaged Gf in each lung region $=\frac{\int_{t_{1}}^{t_{2}} \frac{D p(t)}{D p(0)} d t}{t_{2}-t_{1}}$

where $t_{1}$ and $t_{2}$ are the time when the particle enters and leaves the region of the lung.

\section{Modelling particle deposition in the human respiratory system}

Many mathematical models have been developed to estimate the total and regional lung deposition of particles in recent decades; for example the ICRP model (International Commission on Radiological Protection), the NCRP model
(National Council on Radiation Protection and Measurement), the IDEAL model (Inhalation, Deposition and Exhalation of Aerosols in/from the Lung) or the MPPD model (Multiple-Path Particle Dosimetry) (Asgharian et al. 2001; ICRP and Protection 1994; Koblinger and Hofmann 1990; National Council on Radiation Protection and Measurements 1997). This study utilized the MPPD model to calculate the total and regional lung deposition of particles emitted from each source.

The MPPD model was developed by Asgharian et al. (2001). The software (MPPD software version 2.11) was downloaded via http://www.ara.com/products/mppd.htm. In this study, we used the MPPD model to calculate the deposition fraction of particles by number in three regions of the lung, the extra-thoracic (ET), tracheo-bronchial (TB) and alveolar (AL) regions, and the entire lung for adults. This study used the reference respiratory values for light exercise for Caucasian people during cooking and cleaning activities and for resting (sitting) during smoking and incense burning based on the reference data recommended by ICRP (1994). The input data for the MPPD model are shown in Table 1.

However, the MPPD model may under-estimate the lung deposition of ambient particles if their hygroscopic properties are not taken into account (Vu et al. 2015a). For correction for the influence of particle hygroscopicity, the MPPD curves were modified for both indoor and outdoor particles with a consideration of their hygroscopicity according to an approach introduced by previous studies (Kristensson et al. 2013; Löndahl et al. 2009; Vu et al. 2015a). In this approach, submicron particles which have increased to their equilibrium size by their growth in the regional lung have the same deposition fraction in the respiratory system as hydrophobic particles with an identical size. Because of no information being available for the hygroscopic growth factor for coarse particles, this study only calculated the deposition fraction of submicron particles $(\mathrm{Dp}<1 \mu \mathrm{m})$ by number. However, the
Table 1 Input data to the MPPD model based on the reference respiratory values from ICRP (1994)

\begin{tabular}{|c|c|c|c|c|c|}
\hline \multicolumn{2}{|c|}{ MPPD model input data } & \multicolumn{2}{|c|}{ Cooking, cleaning } & \multicolumn{2}{|c|}{ Smoking, incense burning } \\
\hline & & Man & Woman & Man & Woman \\
\hline \multirow{7}{*}{ Particle properties } & Model & \multicolumn{4}{|c|}{ Yeh/Schum 5-Lobe } \\
\hline & Functional residual capacity $(\mathrm{mL})$ & 3301 & 2681 & 3301 & 2681 \\
\hline & Upper respiratory tract volume $(\mathrm{mL})$ & 50 & 50 & 50 & 50 \\
\hline & Density $\left(\mathrm{g} \mathrm{cm}^{-3}\right)$ & \multicolumn{4}{|c|}{$0.88-1.56$ (by APS/SMPS merging) } \\
\hline & Nanoparticle model & \multicolumn{4}{|c|}{ YES (for particle smaller than $100 \mathrm{~nm}$ ) } \\
\hline & Inhalability adjustment & \multicolumn{4}{|c|}{ YES (for particle larger than $1 \mu \mathrm{m}$ ) } \\
\hline & Geometric standard deviation & 1 & & & \\
\hline \multirow[t]{7}{*}{ Exposure scenario } & Acceleration of gravity $\left(\mathrm{cm} \mathrm{s}^{-2}\right)$ & 981 & 981 & 981 & 981 \\
\hline & Body orientation & Upright & & & \\
\hline & Breathing frequency $\left(\mathrm{min}^{-1}\right)$ & 20 & 21 & 12 & 14 \\
\hline & Tidal volume $(\mathrm{mL})$ & 1250 & 992 & 750 & 464 \\
\hline & Inspiratory fraction & 0.435 & & & \\
\hline & Pause fraction & 0.05 & & & \\
\hline & Breathing scenario & Nasal & Nasal & Nasal & Nasal \\
\hline
\end{tabular}


deposition fraction of submicron particles by number is not significantly different to that of total particles since the submicron particles accounted for more than $99 \%$ of total particles by number.

\section{Results and discussion}

\section{Particle size distributions}

\section{Outdoor/indoor background levels}

The total number concentration for outdoor and indoor levels (with no indoor sources) was $4.2 \pm 2.1 \times 10^{3}$ and 3.3 $\pm 1.3 \times 10^{3}$ particles $\mathrm{cm}^{-3}$, respectively. As shown in Fig. 2, the particle number size distribution of both outdoor and indoor particles appears to be the sum of log-normal size modes. The number mode for outdoor and indoor particle size distributions was 22.9 and $28.4 \mathrm{~nm}$, respectively. The majority of particles by number ( 84.0 and $80.2 \%$ of total outdoor and indoor particles, respectively) was found in the ultrafine size range $(\mathrm{Dp}<100 \mathrm{~nm})$.

\section{Vacuum cleaning}

The peak particle number concentration was $9.4 \times 10^{4}$ particles $\mathrm{cm}^{-3}$, which decreased to $7.08 \times 10^{4}$ particles $\mathrm{cm}^{-3}$ by the 15 th minute after cleaning stopped. The particle number size distribution shows a unimodal distribution with the mode at $19.8 \mathrm{~nm}$. This mode increased to 22.9 and $26.5 \mathrm{~nm}$ at 15 and $30 \mathrm{~min}$ after the activity stopped. More than $98 \%$ of total particles by number was found in the ultrafine particle size range $(\mathrm{Dp}<100 \mathrm{~nm}$ ) during vacuum cleaning. This high number of ultrafine particles emitted from the vacuum cleaner is consistent with previous studies (Géhin et al. 2008; Knibbs et al. 2011; Wu et al. 2011). Knibbs et al. (2011) investigated particle emissions from 21 vacuum cleaners in a flow tunnel and found that the median emission rate of ultrafine particles was $9.92 \times 10^{9}$ particles $\mathrm{cm}^{-3}$ with a median value of count median diameter (CMD) of $25.5 \mathrm{~nm}$.

In term of mass concentration, vacuum cleaning also generated a large fraction of coarse particles. The peak $\mathrm{PM}_{1.0}$, $\mathrm{PM}_{2.5}$ and $\mathrm{PM}_{10}$ mass concentrations were 1.5, 22.7 and $75.4 \mu \mathrm{g} \mathrm{m}^{-3}$. Szymczak et al. (2007) suggested that particles are in part generated by mechanical abrasion of the graphite brushes and copper commutator. However, the major source of ultrafine particles may be due to spark discharging that occurs at voltages above $100 \mathrm{~V}$ between two carbon electrodes within the vacuum cleaner motor (Helsper et al. 1993; Szymczak et al. 2007). Knibbs et al. (2011) reported lower ultrafine particle emissions with two battery-driven vacuum cleaners at lower voltages (14 and $22 \mathrm{~V}$ ).
There are few studies on the chemical properties and morphology of particles emitted from vacuum cleaners. Szymczak et al. (2007) used a MOUDI to collect particles in the size range of $0.057-18.0 \mu \mathrm{m}$ and suggested that ultrafine particles comprise mainly of copper which may be generated from abrasion of the copper commutator inside the motor. Lioy et al. (1999) reported that particles larger than $0.01 \mu \mathrm{m}$ in diameter mainly consist of chemical binders, copper and carbon (elemental and organic) which were induced by rubbing and arcing between carbon rods and the copper commutator. In this study, the effective density of vacuum cleanergenerated particles obtained by the APS/SMPS merging algorithm was $1.16 \mathrm{~g} \mathrm{~cm}^{-3}$ which was much lower than the material density of carbon $\left(\sim 2 \mathrm{~g} \mathrm{~cm}^{-3}\right)$ and copper $\left(8 \mathrm{~g} \mathrm{~cm}^{-3}\right)$. This finding suggests that particles released from the vacuum cleaner motor were possibly carbon internal void aggregates (DeCarlo et al. 2004; Helsper et al. 1993; Lioy et al. 1999) which have a lower effective density.

\section{Kitchen cleaning by soap/W5 spray cleaner}

As seen in Fig. 2, kitchen desk cleaning using organic compounds (brand name, W5 cleaner) generated predominantly ultrafine particles with a maximum concentration of $1.25 \times 10^{5}$ particle $\mathrm{cm}^{-3}$ and a peak number mode of $30.6 \mathrm{~nm}$. As with the vacuum cleaning, the CMD increased and particle number concentration decreased rapidly due to coagulation and deposition processes after the cleaning activity was finished.

Cleaning using chemical cleaners also generated both ultrafine and coarse particles. Average $\mathrm{PM}_{1.0}, \mathrm{PM}_{2.5}$ and $\mathrm{PM}_{10}$ mass concentration during cleaning activity were $2.5,10.4$ and $22.0 \mu \mathrm{g} \mathrm{m}^{-3}$, respectively. On the other hand, nano/ultrafine particles were probably produced by the oxidation and condensation of volatile organic compounds (VOCs) released from the cleaning agent during the cleaning activity (Nazaroff and Weschler 2004; Rohr 2013; Singer et al. 2006a; Zhu et al. 2001). Singer et al. (2006b) reported that a large amount of VOCs were found using pine-oil cleaner. They reported a concentration measured over $1 \mathrm{~h}$ of 10 $1300 \mu \mathrm{g} \mathrm{m}^{-3}$ for individual terpenoids, including $\alpha$ terpinene $\left(90-120 \mathrm{\mu g} \mathrm{m}^{-3}\right)$, d-limonene $(1000-$ $\left.1100 \mu \mathrm{g} \mathrm{m}^{-3}\right)$, terpinolene $\left(900-1300 \mu \mathrm{g} \mathrm{m}^{-3}\right)$ and $\alpha$ terpineol $\left(260-700 \mu \mathrm{g} \mathrm{m}^{-3}\right)$. In addition, Sarwar et al. (2004) found that terpenes from cleaning products can react with ozone, resulting in secondary organic aerosol production in an indoor environment.

This study used W5 orange cleaner, which contains some surface active components (not specified in the detail from the product's label), soap and limonene. In general, limonene has been identified to play an important role in the formation of indoor nanoparticles (Langer et al. 2008; Wainman et al. 2000; Wang et al. 2007b; 

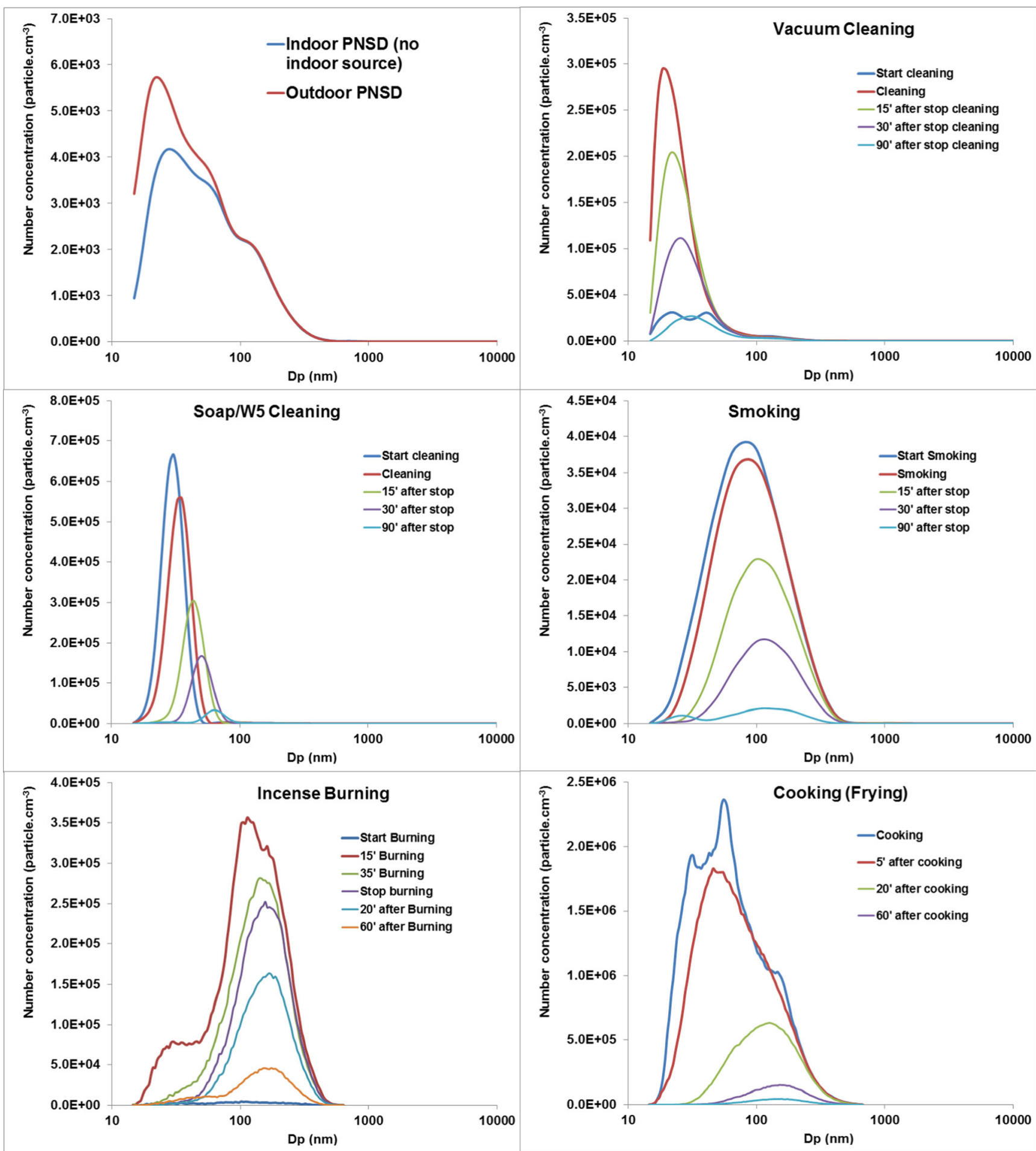

Fig. 2 Particle number size distribution from indoors (without indoor sources) and outdoor environments and five major indoor sources

Waring et al. 2011). Langer et al. (2008) showed that the nucleation and growth of particles from the reaction of $\mathrm{O}_{3}$ and limonene could occur even at low concentration of reactants. The effective density obtained by the APS/ SMPS merging process was $0.88 \mathrm{~g} \mathrm{~cm}^{-3}$, indicating that the majority of particles generated by use of cleaning products were predominantly organic.

\section{Tobacco smoking}

The particle number size distribution from cigarette smoking showed a unimodal structure with a mode at $90 \mathrm{~nm}$ and peak number concentration of $2.89 \times 10^{4}$ particle $\mathrm{cm}^{-3}$ (Note that two cigarettes were simultaneously smoked by regular smokers in this experiment). During the ageing process, the 
CMD increased to $120 \mathrm{~nm}$, as shown in Fig. 2. These results are consistent with previous studies (Hussein et al. 2006; Wu et al. 2011). Wu et al. (2011) measured the submicron particle number size distribution emitted from five brands of cigarettes and found that the number mode ranged from 102.9 to $116.7 \mathrm{~nm}$ with the maximum number concentration of $1.38 \times 10^{6}$ particle $\mathrm{cm}^{-3}$. The number concentration of particles is not only dependent on the emission rate of the source, but also the volume of the chamber or the indoor environment where smoking takes place, and the ventilation.

Fine particles $(\mathrm{Dp}<2.5 \mu \mathrm{m})$ emitted from cigarette smoking were found to make a dominant contribution to mass concentration with an averaged fraction of more than $82 \%$ of total $\mathrm{PM}_{10}$ mass. Averaged $\mathrm{PM}_{1.0}, \mathrm{PM}_{2.5}$ and $\mathrm{PM}_{10}$ concentrations were $3.2,133.6$ and $149.6 \mathrm{\mu g} \mathrm{m}^{-3}$, respectively. In a review of indoor particles, Wallace (1996) indicated that the most important indoor source of fine and coarse particles in the USA was tobacco smoking, with an estimated increase of up to $45 \mathrm{\mu g} \mathrm{m}^{-3}$ in homes with smokers. The effective density of cigarette smoke particles was $1.56 \mathrm{~g} \mathrm{~cm}^{-3}$ based on APS/ SMPS merging results. This value was slightly lower than the material density of black carbon $\left(\sim 2 \mathrm{~g} \mathrm{~cm}^{-3}\right)$ and similar to the effective density of humic acids and humic-like substances (1.54-1.77 $\mathrm{g} \mathrm{cm}^{-3}$ ) from wood burning (Dinar et al. 2006).

\section{Incense burning and cooking}

Incense burning generated a majority of particles in the accumulation mode with a CMD around 110-150 $\mathrm{nm}$. The total number concentration was up to $2.25 \times 10^{5}$ particle $\mathrm{cm}^{-3}$. In the first scan of incense burning, it showed a distinct mode at $30.5 \mathrm{~nm}$, suggesting that some nanoparticles were formed in the first several minutes of burning.

The number size distribution of particles released during incense burning was in agreement with previous studies. $\mathrm{Wu}$ et al. (2011) measured particle number size distributions from five types of incense stick and found that four of them had a CMD ranging from 124.1 to $148.9 \mathrm{~nm}$ and the other had a CMD of $75.5 \mathrm{~nm}$. A similar study conducted by Ji et al. (2010) reported that the peak number mode of incense smoke was $136 \mathrm{~nm}$ which was found to have a larger size distribution in comparison to other combustion processes such as diesel, wood or biomass burning. Unfortunately, the APS sampler had a problem with its inlet during measurement of particle size for incense burning and cooking; hence, this study could not measure the coarse size for incense burning and cooking emissions. In this study, we adopted an effective density of 1.1 and $1.0 \mathrm{~g} \mathrm{~cm}^{-3}$ to convert the aerodynamic to mobility diameter for incense burning and cooking particles respectively based upon Buonanno et al. (2009) and Ji et al. (2010).

Cooking emissions showed a tri-modal distribution with a peak mode at $47.8 \mathrm{~nm}$. After cooking, the peak mode quickly increased to $135.8 \mathrm{~nm}$. The reason is probably related to the ventilation (opened door when people leave kitchen room after cooking activity). During the cooking, a large number of particles were generated with a peak number concentration of $1.57 \times 10^{6}$ particle $\mathrm{cm}^{-3}$. In a review of cooking emission, Abdullahi et al. (2013) reported a large fraction of ultrafine particles released during cooking activity with the peak number mode around 20-100 $\mathrm{nm}$.

\section{Hygroscopic growth factor of particles}

\section{Hygroscopic growth factor of outdoor and indoor particles} when no indoor source was present

The hygroscopic growth factors $\left(G_{f}\right)$ of outdoor and indoor particles at an initial dry diameter of 50, 100 and $200 \mathrm{~nm}$ were measured during periods when no indoor source was present, from 15 to 21 August, 2014. The growth factor probability density function $\left(\mathrm{G}_{\mathrm{f}}-\mathrm{PDF}\right)$ of each particle size from the outdoor and indoor environments is shown in Fig. 3. For the particle size of 50 and $100 \mathrm{~nm}$, two fractions of nearly hydrophobic $\left(\mathrm{G}_{\mathrm{f}} \sim 1.01-1.11\right)$ and less-hygroscopic particles $\left(\mathrm{G}_{\mathrm{f}}\right.$ $\sim 1.11-1.33$ ) were found dominant in both indoor and outdoor environments. For the particle size of $200 \mathrm{~nm}$, the main fractions of particles were less-hygroscopic and morehygroscopic particles $\left(\mathrm{G}_{\mathrm{f}} \sim 1.11-1.85\right)$. Mean growth factors for outdoor particles were $1.15 \pm 0.07,1.17 \pm 0.09$ and $1.23 \pm$ 0.10 for the particle sizes of 50, 100 and $200 \mathrm{~nm}$, respectively. The mean growth factors for indoor particles were slightly higher than those of outdoor particles with values of $1.16 \pm$ 0.07 and $1.18 \pm 0.09$ for particles with a diameter of 50 and $100 \mathrm{~nm}$, respectively. The loss of semi-volatile organic constituents due to volatilization or uptake on the indoor wall surface during the penetration from the outdoor to indoor environment could explain the small decrease of the fraction of nearly hydrophobic particles in the indoor environment when no indoor source was present. On the other hand, the mean growth factor for indoor particles with a diameter of $200 \mathrm{~nm}$ was $1.22 \pm 0.07$ which was practically the same as the growth factor for outdoor particles $(1.23 \pm 0.10)$.

Hygroscopic growth factor of particles generated from indoor sources

Figure 4 shows the hygroscopic growth factor of particles emitted from five indoor sources at three particle sizes of 50, 100 and $200 \mathrm{~nm}$. Particles generated from vacuum cleaning were found to be "nearly hydrophobic" with an average growth factor $\left(\mathrm{G}_{\mathrm{f}}\right)$ around $0.98-1.10$ for particle sizes of 50 and $100 \mathrm{~nm}$. This finding is in agreement with the discussed hypothesis that particles emitted from the vacuum cleaner mainly comprise carbon and copper as discussed above. The growth factor of particles of $200 \mathrm{~nm}$ was 1.16 which is higher 
Fig. 3 Hygroscopic growth factor probability density function $\left(\mathrm{G}_{\mathrm{f}}-\mathrm{PDF}\right)$ for outdoor $(l e f t)$ and indoor (right) particles

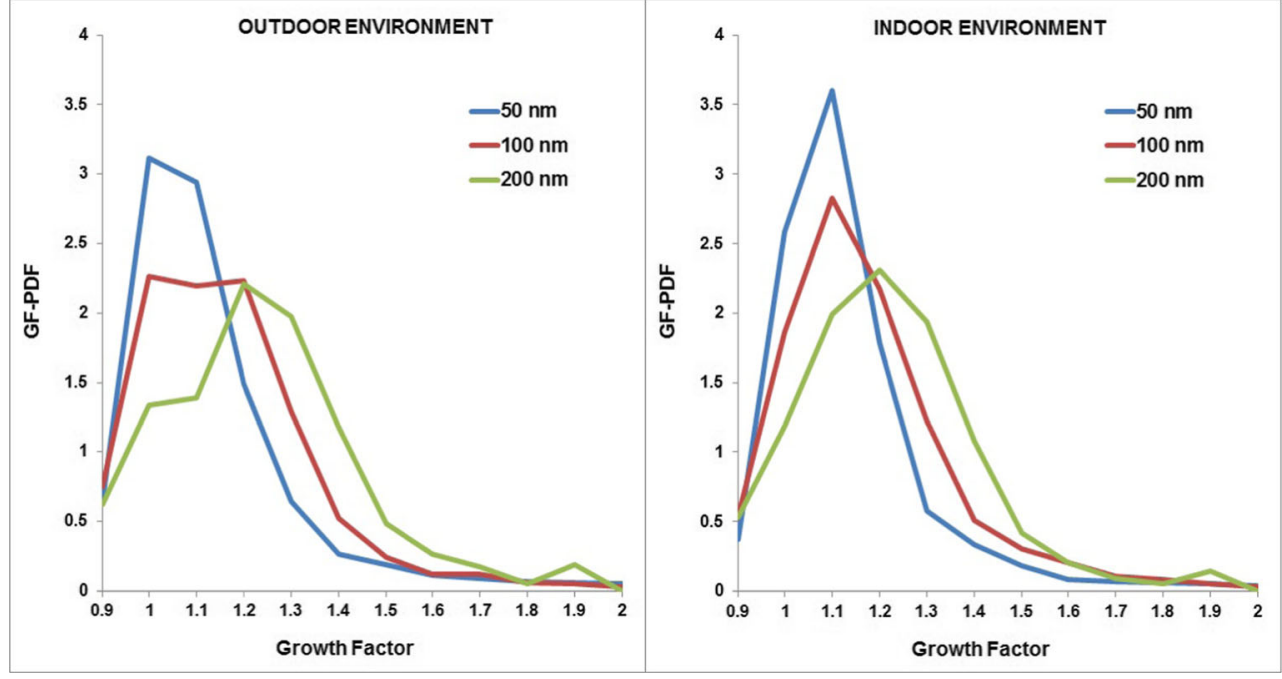

than those for smaller particles due to the mix of particles generated from the vacuum cleaner motor and background.

Particles emitted from Soap/W5 cleaner were found to be "less-hygroscopic" $\left(\mathrm{G}_{\mathrm{f}} \sim 1.12-1.15\right.$ for particles at 50 and $100 \mathrm{~nm}$ ). This finding is consistent with the above suggestion that the ultrafine particles generated by cleaning activities using W5 cleaner predominantly consist of organic compounds such as the products of oxidation of limonene. Virkkula et al. (1999) conducted a measurement of hygroscopic properties of aerosol formed by oxidation of limonene, $\alpha$-pinene and $\beta$-pinene and found that the hygroscopic growth factor was approximately 1.10 at $84 \% \mathrm{RH}$, consistent with our results. The hygroscopic growth factor of particles of $200 \mathrm{~nm}$ was 1.22 . This high growth factor could also be explained by the mix of particles generated from cleaning activities and background in the large size range, while the majority of particles during this activity were found in the ultrafine size range.

The average hygroscopic growth factors of particles emitted from cigarette smoking were approximately
1.01-1.04 for all sizes of 50, 100 and $200 \mathrm{~nm}$. This hygroscopic growth factor is found slightly higher than diesel combustion $\left(\mathrm{G}_{\mathrm{f}} \sim 1.01\right)$, but lower than biomass burning $\left(\mathrm{G}_{\mathrm{f}} \sim 1.04-1.10\right)$. This low hygroscopic growth factor is probably due to the chemical properties of particles generated from combustion, which mainly comprise black carbon and organic compounds. Morawska et al. (2005) found a similar count median diameter for both inhaled and exhaled submicron particles, suggesting that the change in particle size after its travel into the lung is not significant. However, the lack of growth of particles cannot be concluded with certainty due to different temperature and humidity regimes between the chamber and the lung. Li and Hopke (1993) found the hygroscopic growth factor of cigarette mainstream and sidestream smoke particles at $200 \mathrm{~nm}$ was approximately 1.40 1.42 at RH $99.5 \%$ which was slightly higher than the estimated growth factor value in our study $\left(\mathrm{G}_{\mathrm{f}} \sim 1.3\right.$ for $\mathrm{Dp}=200 \mathrm{~nm}$ at $99.5 \%$ humidity calculated from $\mathrm{G}_{\mathrm{f}}$ $\sim 1.04$ at $90 \%$ measured by HTDMA).

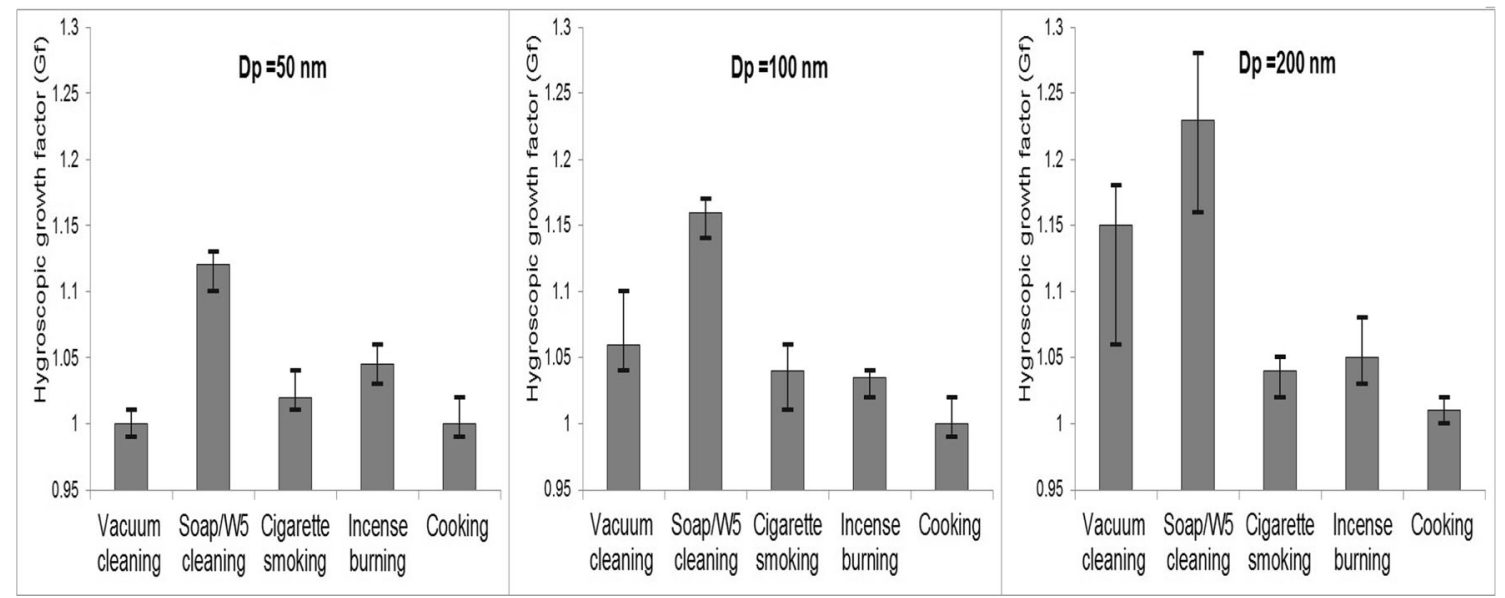

Fig. 4 Hygroscopic growth factor of particles generated from different indoor sources 
Similarly, particles emitted from incense burning were found to be nearly hydrophobic with the hygroscopic growth factors ranging from 1.01 to 1.05 for all particle sizes of 50 , 100 and $200 \mathrm{~nm}$. A dominance of carbonaceous particles released from incense burning can explain those low hygroscopic growth factors. Wang et al. (2007a) measured the characteristics of air pollutants from incense burning in two temples in Hong Kong and found that the organic and elemental carbon accounted for around $60 \%$ of $\mathrm{PM}_{2.5}$ mass, while inorganic ion species only accounted for $12 \%$ of $\mathrm{PM}_{2.5}$ mass. Li and Hopke (1993) predicted that the hygroscopic growth factor of particles at $99.5 \% \mathrm{RH}$ from the burning of incense was around 1.45 and 1.7 for particle sizes of 100 and $200 \mathrm{~nm}$ while the values in our estimation were much lower $\left(\mathrm{G}_{\mathrm{f}} \sim 1.16\right.$ and 1.31 for particles of 100 and $200 \mathrm{~nm}$ at $99.5 \%$ RH). Li and Hopke (1993) indicated that $8 \%$ errors were found in their estimation of the hygroscopic growth ratio mainly due to the humidity uncertainty in their HTDMA system. Furthermore, variations in particle composition and influences of the local environment may account for differences when measuring the hygroscopic growth factor of combustion aerosols.
Particles generated from cooking activity were found to be nearly hydrophobic $\left(\mathrm{G}_{\mathrm{f}} \sim 1.0-1.02\right.$ for all particle sizes of 50 , 100 and $200 \mathrm{~nm}$ ). In our study, we performed the cooking experiments by frying sausages with sunflower oil and toasting bread. This result is consistent with Dua and Hopke (1996), who observed that there was no growth of particles emitted from cooking oils and sweet Italian sausages.

\section{Growth factors of particles in the lung}

The mean growth factors for particles from outdoors, indoors without indoor sources, and five major indoor sources in their maximum growth at $99.5 \%$ and different regions of the lung are shown in Fig. 5.

As discussed above, the hygroscopic properties of particles arising from different indoor activities show different characteristics. Particles generated from soap/W5 cleaning products show a more hygroscopic tendency than particles from indoor combustion sources. Particles emitted from cooking activities show no significant growth in all sizes. When particles penetrate into the respiratory tract, the particles with diameter below $200 \mathrm{~nm}$ can quickly reach their equilibrium size in all lung regions. For

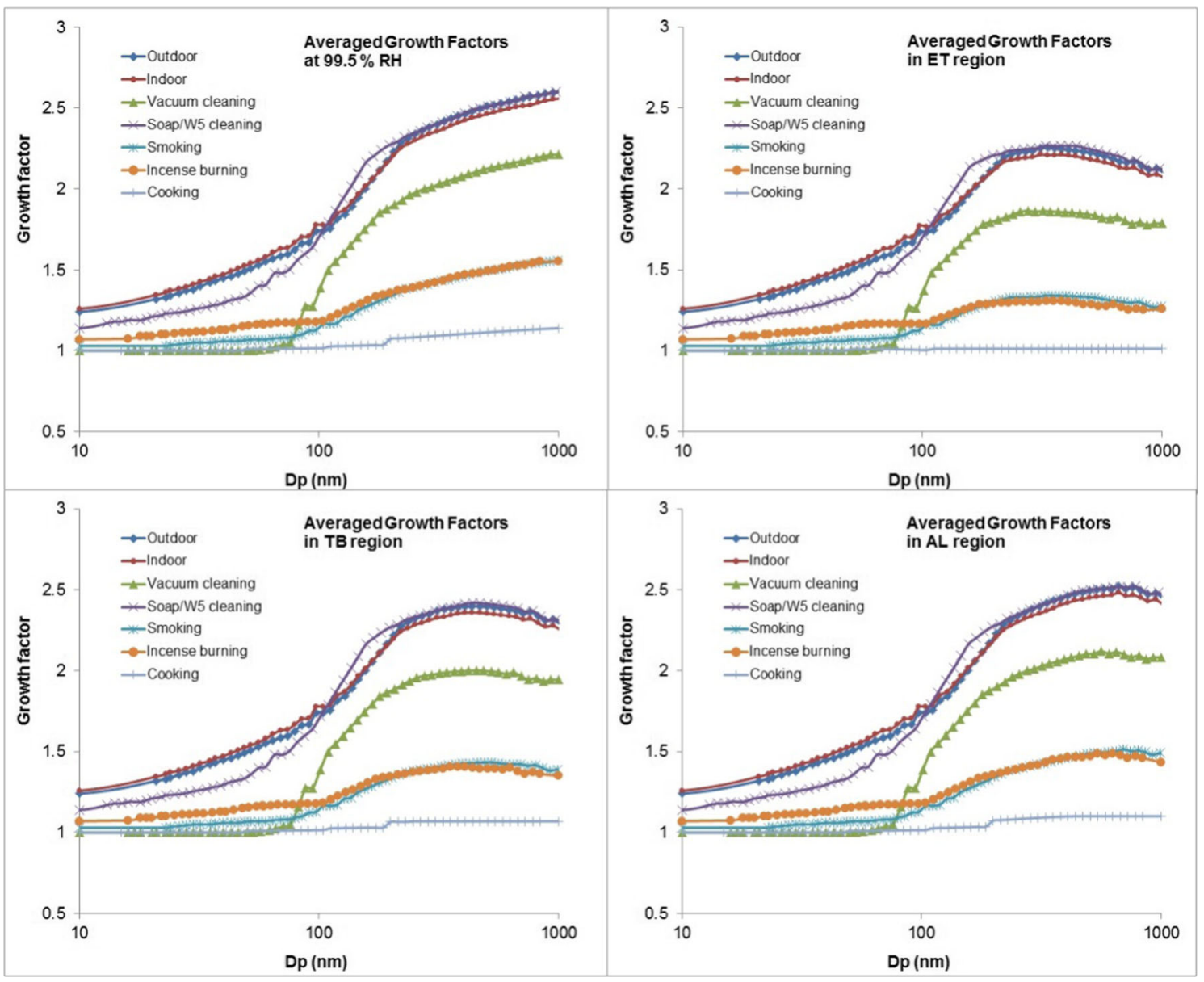

Fig. 5 Modelled hygroscopic growth factors at $99.5 \% \mathrm{RH}$ and in different regions of the lung 
particles larger than $400 \mathrm{~nm}$, growth factors in the ET region can be more than $10 \%$ lower than those in the $\mathrm{AL}$ region.

\section{Effects of particles from indoor sources on lung dose of particles}

\section{MPPD models for different genders and activities}

Based on the MPPD model, the deposition fraction curves of hydrophobic particles for man and woman in light exercise and resting are shown in Fig. 6. The total deposition fraction was found to be slightly greater for men than women when resting. Specifically, the deposition fraction of ultrafine particles in the AL regions was found greater by up to 1.35 times higher for men compared with women. On the other hand, there was no significant difference between the lung deposition fractions for men and women during light exercise.

\section{Regional lung deposition of particles emitted from each source}

Total and regional lung deposition fractions of outdoor and indoor particles (with and without indoor source particles) for adults (male and female) by number are shown in Fig. 7. The fractional total lung deposition fraction for outdoor particles and indoor particles (without indoor sources) was $0.49 \pm 0.06$ and $0.45 \pm 0.05$. The slightly lower total deposition of particles from the indoor environment compared to the outdoor environment was due to the shift of the outdoor particle number size distribution to a larger size range when they penetrate from outdoor to indoor environments. For both environments, a dominant fraction of particles deposited in the AL region $(59.1 \%)$, followed by the TB region $(23.9 \%)$. There was only $15.7 \%$ of particle number deposited in the ET region.
For the indoor sources, the lung deposition of particles alters mainly due to the change of size distribution. Up to 66.2 and $72.6 \%$ of total particles deposit in the lung during soap/W5 cleaning and vacuum cleaning. This can be explained by a majority of particles released during cleaning activities being present as nanoparticles which easily penetrate into the deeper region of the lung. In contrast, the lung deposition fraction of particles emitted from indoor combustion sources such as cooking, incense burning or smoking was lower because the main fraction of particle number was found in the larger size range, particularly in the Aitken range for cooking and the accumulation mode for incense burning or cigarette smoke. The total lung deposition fraction was $0.49 \pm$ $0.02,0.32 \pm 0.03$ and $0.37 \pm 0.03$ for indoor particles generated during cooking, incense burning and smoking. For those particles, a predominance of deposited particle number was found in the AL region (56.7-68.1\%), followed by the TB region (19.5-27.0\%). Only $12.2-16.2 \%$ of total deposited particles by number was found in the ET region.

Discussion on the contribution of indoor sources to lung dose of aerosols

In order to determine and compare the effects of indoor sources upon human exposure, this study has compared the lung dose rate of particle number in the indoor environment with and without indoor activities. The lung dose of particle number in different regions of the lung (i) within a specific particle size range was calculated based on the following equation (Hussein et al. 2013):

Dose $_{\mathrm{i}}=V_{E} \times D F_{i} \times C_{N} \times \Delta t$

where $V_{\mathrm{E}}$ is the minute ventilation $\left(\mathrm{m}^{3} \min ^{-1}\right) ; \mathrm{DF}_{i}$ is the deposited fraction of particles in the different regions of the
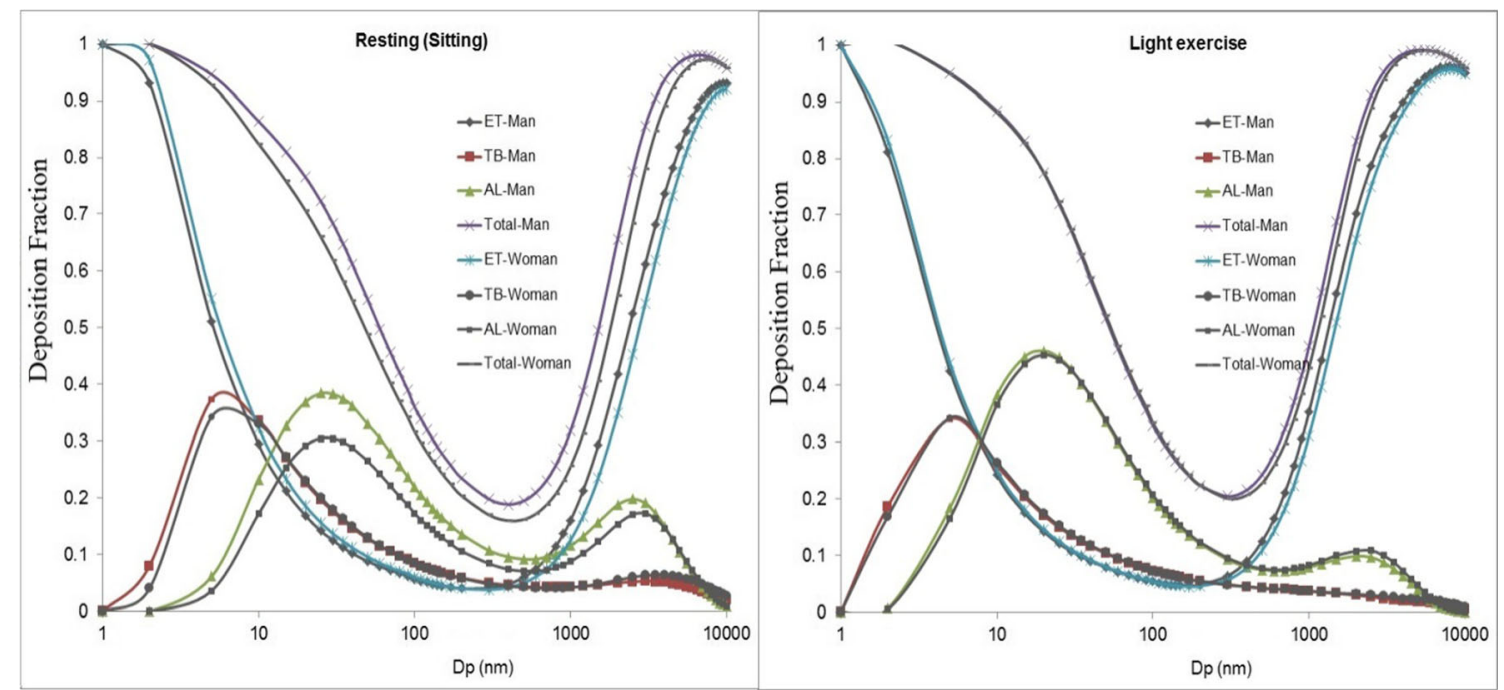

Fig. 6 Deposition fraction curve from MPPD model for man and woman in resting and light exercise 
Fig. 7 Deposition fraction of particle number in regions of the lung for adults

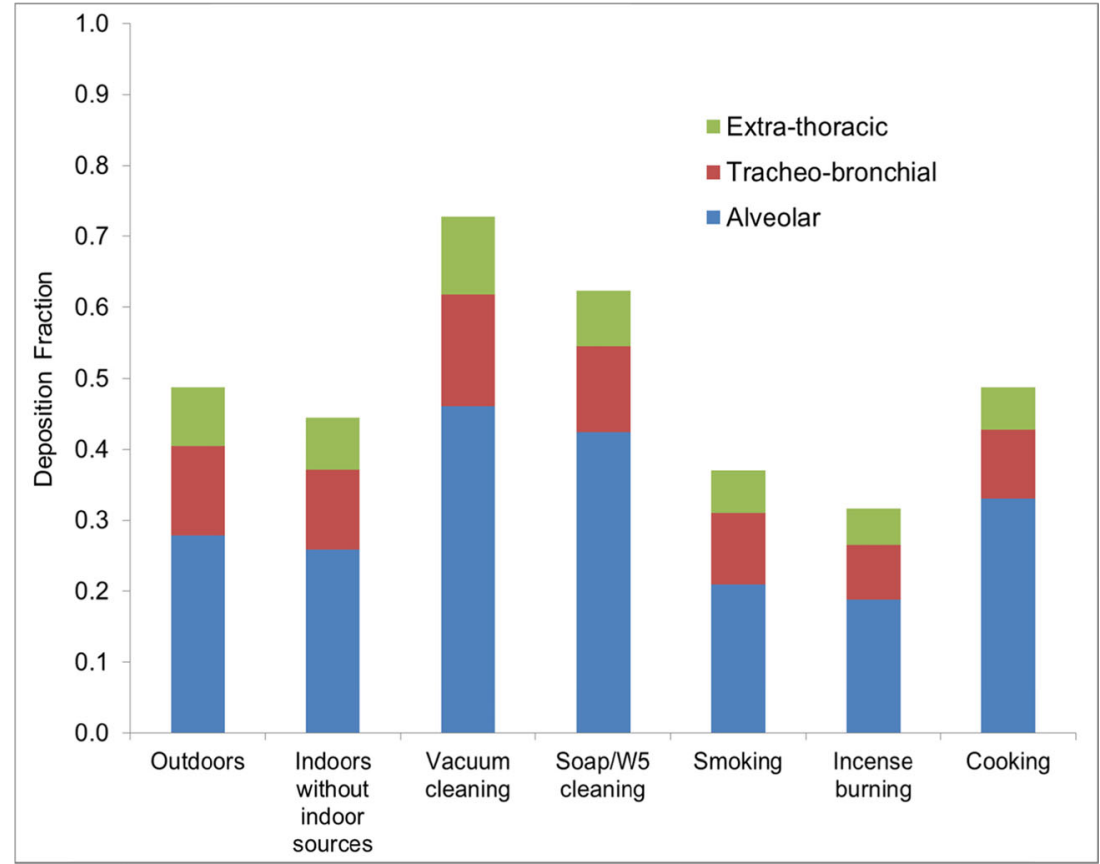

human respiratory tract; $C_{N}$ is the total number concentration (particle $\mathrm{cm}^{-3}$ ); $\Delta t$ is the exposure time period (minutes). The respiratory tract deposition particle dose rate which is defined as the total particle number deposited in the respiratory system during a specific time period (in this study, $\Delta t$ was set up to $1 \mathrm{~min}$ ), can be estimated from:

Minute dose rate r $_{\mathrm{i}}=\mathrm{V}_{E} \times D F_{\mathrm{i}} \times \mathrm{C}_{\mathrm{N}}$

$V_{\mathrm{E}}$ was set at $7.75 \times 10^{-3}$ for sitting and $2.29 \times$ $10^{-2} \mathrm{~m}^{3} \mathrm{~min}^{-1}$ for light exercise calculated by averaging the respective VE values for men and women at two exercise levels (sitting and light exercise) (ICRP 1994).

Table 2 shows the minute dose rate of particles by number for adults in the outdoor and indoor environment (with and without indoor sources). During indoor activities, humans can be exposed to a huge number of particles. For example, a person when cooking could have an exposure of more than $1.76 \times 10^{10}$ particles every minute, which is a thousand times higher than the exposure value for outdoor particles $(14.2 \times$ $10^{6}$ particles). The $1-\mathrm{min}$ dose of cooking particles by number at the light exercise level is equivalent to 18.3 and $6.2 \mathrm{~h} \mathrm{ex-}$ posure to outdoor particles at the resting and exercise respiration rate, respectively.

Similarly, the total minute lung dose of particles from vacuum cleaning, soap/W5 cleaning, smoking and incense burning could be up to $1.6 \times 10^{9}, 2.1 \times 10^{9}, 8.3 \times 10^{7}, 5.5 \times 10^{8}$ particle $\min ^{-1}$. Based on Eq. (7), it is clear that the minute lung dose rate of particles strongly depends upon $V_{\mathrm{E}}, D F_{i}$ and $C_{N}$. While the total $\mathrm{DF}_{i}$ for particles from the different indoor sources had a range of 0.32 (for incense burning) to
Table 2 Lung deposition of particles from outdoor and indoor environments (without and with indoor sources) for adults (averaged deposition fraction for both man and woman)

\begin{tabular}{|c|c|c|c|c|c|c|c|c|c|}
\hline & \multicolumn{4}{|c|}{ Deposition fraction } & \multirow{2}{*}{$\begin{array}{l}V_{\mathrm{E}} \\
\left(\mathrm{m}^{3} \min ^{-1}\right)\end{array}$} & \multicolumn{4}{|c|}{ Dose $\left(10^{6}\right.$ particles $\left.\min ^{-1}\right)$} \\
\hline & $\mathrm{AL}$ & $\mathrm{TB}$ & ET & Total & & $\mathrm{AL}$ & TB & TB & Total \\
\hline Outdoors & 0.28 & 0.13 & 0.08 & 0.49 & $7.75 \mathrm{E}-03$ & 9.0 & 4.0 & 2.6 & 16.1 \\
\hline Indoors $^{\mathrm{a}}$ & 0.26 & 0.11 & 0.07 & 0.45 & $7.75 \mathrm{E}-03$ & 6.6 & 2.9 & 1.9 & 11.4 \\
\hline $\begin{array}{l}\text { Vacuum } \\
\text { cleaning }\end{array}$ & 0.46 & 0.16 & 0.11 & 0.73 & $2.29 \mathrm{E}-02$ & 992.5 & 338.2 & 238.0 & 1568.3 \\
\hline $\begin{array}{c}\text { Soap/W5 } \\
\text { cleaning }\end{array}$ & 0.42 & 0.12 & 0.08 & 0.62 & $2.29 \mathrm{E}-02$ & 1419.3 & 406.9 & 258.4 & 2084.5 \\
\hline Smoking & 0.21 & 0.10 & 0.06 & 0.37 & $7.75 \mathrm{E}-03$ & 47.1 & 21.5 & 13.7 & 82.9 \\
\hline Incense burning & 0.19 & 0.08 & 0.05 & 0.32 & $7.75 \mathrm{E}-03$ & 328.7 & 128.3 & 86.6 & 549.5 \\
\hline Cooking & 0.33 & 0.10 & 0.06 & 0.49 & $2.29 \mathrm{E}-02$ & $11,874.5$ & 3413.3 & 2159.0 & $17,630.0$ \\
\hline
\end{tabular}

$V_{E}$ ventilation rate (minute ventilation)

${ }^{a}$ Indoor environment with no indoor sources 
0.73 (for vacuum cleaning) and the minute ventilation rate for a male adult can range by nearly 6.7 times from $7.5 \times 10^{-3}$ to $5 \times 10^{-2} \mathrm{~m}^{3} \mathrm{~min}^{-1}$ (ICRP 1994), the concentration of particles by number was found to show the largest variation from $3.3 \times 10^{3}$ (for indoor environment with no source) to $1.57 \times 10^{6}$ (for cooking emission) particle $\mathrm{cm}^{-3}$. This suggests that the concentration level is the main factor controlling the lung dose.

Indoor particles not only contribute a large fraction of human exposure to aerosols during indoor activities, but also after indoor activities. Figure 8 shows the evolution of minute lung dose rate, concentration and lung deposition fraction of indoor particles after finishing indoor activities under low ventilation conditions (closed windows and door after indoor generation). It is found that the total concentration and minute lung dose decrease dramatically after stopping indoor particle generation, but the minute lung dose was still very high within $30 \mathrm{~min}$, especially for cleaning activities. Because of deposition, coagulation and the mixing with outdoor particles due to air exchange, the size was also changed, altering the lung deposition fraction. For cleaning activities, the lung deposition fraction decreased to that of average indoor particles without indoor sources. For incense burning and passive smoking, the lung deposition fraction firstly decreased within around the first 30 min after finishing indoor activities, but then increased to the background level. This can be explained due to the deposition of particles on kitchen surfaces in the first 20 30 min which shifts the particle size distributions to a larger size. Subsequently, the mixing with outdoor particles which have a smaller size than incense burning and smoking aerosols moves the particle number size distribution to the smaller size range, consequently affecting deposition fraction.

\section{Uncertainty for minute dose rate calculation}

As shown in Eq. (8), the uncertainty for minute dose rate calculation depends upon the variation of minute ventilation $\left(V_{\mathrm{E}}\right)$, deposition fraction (DF) and particle number concentration $\left(C_{N}\right)$. In this study, the minute ventilation is assumed as a constant value for each activity. Therefore, the uncertainty in the minute dose rate calculation can be estimated from the uncertainties in the lung deposition fraction and particle number concentration. The relative standard error of lung deposition fractions of particles generated from each indoor source
Fig. 8 Minute lung dose, concentration and lung deposition fraction of particles after indoor activities

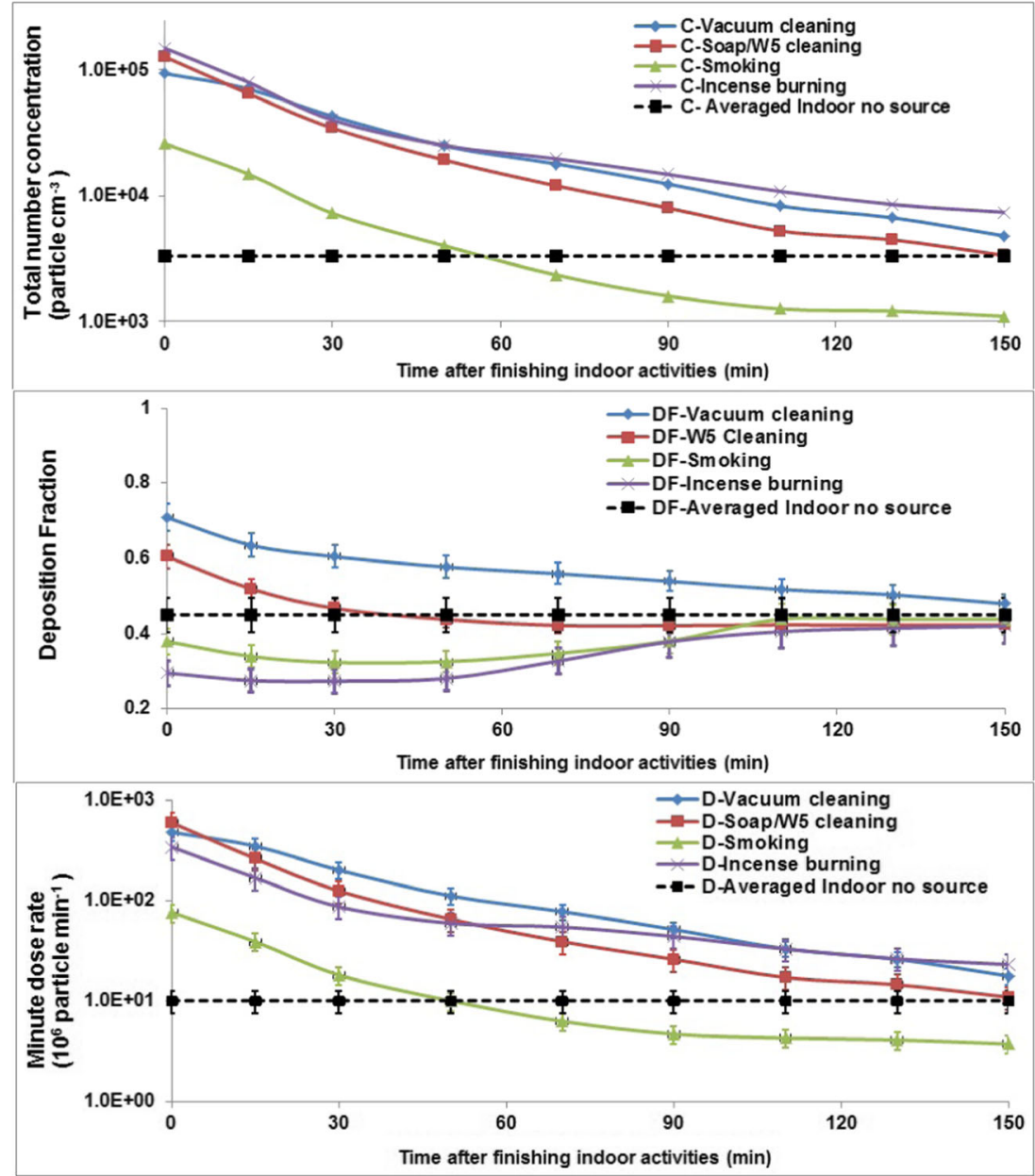


mainly depends on the variation of input size distribution and subject difference such as gender and lung structure. Since the MPPD model does not provide estimates of uncertainty, this study could only estimate the errors caused by the variation of particle number size distribution and gender. The estimated relative standard deviations of total lung deposition fraction calculated for vacuum cleaning, soap/W5 cleaning, smoking, incense burning and cooking particles were 2.7, 4.8, 8.1, 9.4 and $4.1 \%$, respectively.

The uncertainty in particle number concentrations measured for each source depends on the variation of particle number concentrations obtained by each SMPS measurement scan during the period of indoor source generation. The cleaning, smoking, incense burning and cooking experiments were performed during a period of approximately 10, 5, 60 and $20 \mathrm{~min}$, respectively. Each SMPS measurement combined two SMPS scans during $5 \mathrm{~min}$. The relative standard deviation was estimated by dividing the standard deviation by the average number concentration of particles measured during each activity. The estimated relative standard deviation for particle number concentration measurement was 17.4, 9.4, 7.1, 22.3, and $14.4 \%$ for vacuum cleaning, soap/W5 cleaning, smoking, incense burning and cooking measurements. By combination of the relative standard deviation for lung deposition fractions and particle number concentrations, the uncertainty in the minute lung dose rate was estimated as 17.6, 10.6, 10.8, 24.2 and $15.0 \%$, respectively. Clearly, the uncertainty in minute lung dose rate depends mainly upon the variation of particle number concentration.

\section{Conclusion}

Particles released from indoor activities have many physical properties such as concentration, particle size, particle density and hygroscopicity which are relevant to determining lung deposition. Particles generated from vacuum cleaning and soap/W5 cleaning are mainly distributed in the nano size range while those from incense burning and cigarette smoking were found predominantly in the accumulation mode, and those from cooking activity were found in the Aitken mode. Most of the particles released from indoor sources were nearly hydrophobic, except the particles from soap/W5 cleaning that were less-hygroscopic. Particles from cleaning activities showed very high total lung deposition fraction by number. This was up to 0.73 and 0.66 for vacuum cleaner and soap/W5 cleaning particles, respectively.

Particles are predicted to deposit by number mainly in the $\mathrm{AL}$ region, followed by the TB region. This study found that people could be exposed to high aerosol concentrations due to indoor sources. The minute lung dose of particles during indoor source episodes was found to be much greater than the indoor background level without an indoor source. The total minute lung dose rate of particles from vacuum cleaning, soap/W5 cleaning, smoking and incense burning could be up to $1.6 \times 10^{9}, 2.2 \times 10^{9}, 7.2 \times 10^{7}$ and $5.4 \times 10^{8}$ particles $\mathrm{min}^{-1}$, respectively, while those for average outdoor and indoor background levels were $1.4 \times 10^{7}$ and $1.0 \times 10^{7}$ particles $\min ^{-1}$. This suggests that indoor sources may make the main contribution to the total lung dose of indoor particles expressed by number.

Acknowledgments This Research is supported by European Union through the 7th Framework Programme HEXACOMM, FP7/20072013 under grant agreement No. 315760.

Open Access This article is distributed under the terms of the Creative Commons Attribution 4.0 International License (http:// creativecommons.org/licenses/by/4.0/), which permits unrestricted use, distribution, and reproduction in any medium, provided you give appropriate credit to the original author(s) and the source, provide a link to the Creative Commons license, and indicate if changes were made.

\section{References}

Abdullahi KL, Delgado-Saborit JM, Harrison RM (2013) Emissions and indoor concentrations of particulate matter and its specific chemical components from cooking: a review. Atmos Environ 71:260-294

Asgharian B, Hofmann W, Bergmann R (2001) Particle deposition in a multiple-path model of the human lung. Aerosol Sci Technol 34: 332-339

Beddows DCS, Dall'Osto M, Harrison RM (2010) An enhanced procedure for the merging of atmospheric particle size distribution data measured using electrical mobility and time-of-flight analysers. Aerosol Sci Technol 44:930-938

Bhangar S, Mullen N, Hering S, Kreisberg N, Nazarof W (2011) Ultrafine particle concentrations and exposures in seven residences in northern California. Indoor Air 21:132-144

Buonanno G, Morawska L, Stabile L (2009) Particle emission factors during cooking activities. Atmos Environ 43:3235-3242

DeCarlo PF, Slowik JG, Worsnop DR, Davidovits P, Jimenez JL (2004) Particle morphology and density characterization by combined mobility and aerodynamic diameter measurements. Part 1: theory. Aerosol Sci Technol 38:1185-1205

Delgado-Saborit JM, Aquilina NJ, Meddings C, Baker S, Harrison RM (2011) Relationship of personal exposure to volatile organic compounds to home, work and fixed site outdoor concentrations. SciTot Environ 409:478-488

Diffey BL (2011) An overview analysis of the time people spend outdoors. British J Dermatol 164:848-854

Dinar E, Mentel TF, Rudich Y (2006) The density of humic acids and humic like substances (HULIS) from fresh and aged wood burning and pollution aerosol particles. Atmos Chem Phy 6:5213-5224

Donaldson K, Li X, MacNee W (1998) Ultrafine (nanometre) particle mediated lung injury. J Aerosol Sci 29:553-560

Dua S, Hopke P (1996) Hygroscopic growth of assorted indoor aerosols. Aerosol Sci Technol 24:151-160

Ferron G (1977) The size of soluble aerosol particles as a function of the humidity of the air. Application to the human respiratory tract. J Aerosol Sci 8:251-267

Géhin E, Ramalho O, Kirchner S (2008) Size distribution and emission rate measurement of fine and ultrafine particle from indoor human activities. Atmos Environ 42:8341-8352 
Gysel M, McFiggans G, Coe H (2009) Inversion of tandem differential mobility analyser (TDMA) measurements. J Aerosol Sci 40:134-151

He C, Morawska L, Hitchins J, Gilbert D (2004) Contribution from indoor sources to particle number and mass concentrations in residential houses. Atmos Environ 38:3405-3415

Helsper C, Mölter W, Löffler F, Wadenpohl C, Kaufmann S, Wenninge G (1993) Investigations of a new aerosol generator for the production of carbon aggregate particles. Atmos Environ 27:1271-1275

Hussein T, Löndahl J, Passonen P, Koivisto AJ, Petäjä T, Hämeri K, Kulmala M (2013) Modelling regional deposited dose of submicron aerosol particles. Sci Tot Environ 458:140-149

Hussein T, Glytsos T, Ondráček J, Dohányosová P, Ždímal V, Hämeri K, Lazaridis M, Smolík J, Kulmala M (2006) Particle size characterization and emission rates during indoor activities in a house. Atmos Environ 40:4285-4307

ICRP, Protection, I.C.o.R (1994) ICRP Publication 66: Human respiratory tract model for radiological protection. Elsevier Health Sciences

Ji X, Le Bihan O, Ramalho O, Mandin C, D'Anna B, Martinon L, Nicolas M, Bard D, Pairon JC (2010) Characterization of particles emitted by incense burning in an experimental house. Indoor Air 20:147-158

Knibbs LD, He C, Duchaine C, Morawska L (2011) Vacuum cleaner emissions as a source of indoor exposure to airborne particles and bacteria. Environ Sci Technol 46:534-542

Koblinger L, Hofmann W (1990) Monte Carlo modeling of aerosol deposition in human lungs. Part I: simulation of particle transport in a stochastic lung structure. J Aerosol Sci 21:661-674

Kristensson A, Rissler J, Löndahl J, Johansson C, Swietlicki E (2013) Size-resolved respiratory tract deposition of sub-micrometer aerosol particles in a residential area with wintertime wood combustion. Aerosol Air Qual Res 13:24-35

Langer S, Moldanová J, Arrhenius K, Ljungström E, Ekberg L (2008) Ultrafine particles produced by ozone/limonene reactions in indoor air under low/closed ventilation conditions. Atmos Environ 42: 4149-4159

Li W, Hopke P (1993) Initial size distributions and hygroscopicity of indoor combustion aerosol particles. Aerosol Sci Technol 19:305-316

Lioy PJ, Wainman T, Zhang J, Goldsmith S (1999) Typical household vacuum cleaners: the collection efficiency and emissions characteristics for fine particles. JAWMA 49:200-206

Löndahl J, Massling A, Swietlicki E, Bräuner EV, Ketzel M, Pagels J, Loft S (2009) Experimentally determined human respiratory tract deposition of airborne particles at a busy street. Environ Sci Technol 43:4659-4664

National Council on Radiation Protection and Measurement (1997). Deposition, retention, and dosimetry of inhaled radioactive substances: recommendations of the National Council on Radiation Protection and Measurements. National Council on Radiation Protection and Measurements

Morawska L, Hofmann W, Hitchins-Loveday J, Swanson C, Mengersen K (2005) Experimental study of the deposition of combustion aerosols in the human respiratory tract. J Aerosol Sci 36:939-957

Morawska L, Afshari A, Bae G, Buonanno G, Chao C, Hänninen O, Hofmann W, Isaxon C, Jayaratne E, Pasanen P (2013) Indoor aerosols: from personal exposure to risk assessment. Indoor Air 23:462-487

Nazaroff WW, Weschler CJ (2004) Cleaning products and air fresheners: exposure to primary and secondary air pollutants. Atmos Environ 38:2841-2865
Ogulei D, Hopke P, Wallace L (2006) Analysis of indoor particle size distributions in an occupied townhouse using positive matrix factorization. Indoor Air 16:204-215

Rissler J, Svenningsson B, Fors EO, Bilde M, Swietlicki E (2010) An evaluation and comparison of cloud condensation nucleus activity models: predicting particle critical saturation from growth at subsaturation. J Geophys Res: Atmospheres 115:1984-2012

Rohr AC (2013) The health significance of gas- and particle-phase terpene oxidation products: a review. Environ Intl 60:145-162

Sarwar G, Olson DA, Corsi RL, Weschler CJ (2004) Indoor fine particles: the role of terpene emissions from consumer products. JAWMA 54: 367-377

Singer BC, Coleman BK, Destaillats H, Hodgson AT, Lunden MM, Weschler CJ, Nazaroff WW (2006a) Indoor secondary pollutants from cleaning product and air freshener use in the presence of ozone. Atmos Environ 40:6696-6710

Singer BC, Destaillats H, Hodgson AT, Nazaroff WW (2006b) Cleaning products and air fresheners: emissions and resulting concentrations of glycol ethers and terpenoids. Indoor Air 16:179-191

Szymczak W, Menzel N, Keck L (2007) Emission of ultrafine copper particles by universal motors controlled by phase angle modulation. J Aerosol Sci 38:520-531

Thatcher TL, Layton DW (1995) Deposition, resuspension, and penetration of particles within a residence. Atmos Environ 29:1487-1497

Virkkula A, Van Dingenen R, Raes F, Hjorth J (1999) Hygroscopic properties of aerosol formed by oxidation of limonene, $\alpha$-pinene, and $\beta$ pinene. J Geophys Res: Atmospheres 104:3569-3579

Vu TV, Delgado-Saborit JM, Harrison RM (2015a) A review of hygroscopic growth factors of submicron aerosols from different sources and its implication for calculation of lung deposition efficiency of ambient aerosols. Air Qual Atmos Health. doi:10.1007/s11869-0150365-0

Vu TV, Delgado-Saborit JM, Harrison RM (2015b) Review: particle number size distributions from seven major sources and implications for source apportionment studies. Atmos Environ 122:114-132

Wainman T, Zhang J, Weschler CJ, Lioy PJ (2000) Ozone and limonene in indoor air: a source of submicron particle exposure. Environm Health Perspect 108:1139-1145

Wallace L (1996) Indoor particles: a review. JAWMA 46:98-126

Wang B, Lee SC, Ho KF, Kang YM (2007a) Characteristics of emissions of air pollutants from burning of incense in temples, Hong Kong. Sci Tot Environ 377:52-60

Wang S, Ang HM, Tade MO (2007b) Volatile organic compounds in indoor environment and photocatalytic oxidation: state of the art. Environ Intl 33:694-705

Waring MS, Wells JR, Siegel JA (2011) Secondary organic aerosol formation from ozone reactions with single terpenoids and terpenoid mixtures. Atmos Environ 45:4235-4242

Wu C, Chao CY, Sze-To G, Wan M, Chan T (2011). Ultrafine particle emissions from cigarette smouldering, incense burning, vacuum cleaner motor operation and cooking. Indoor Built Environ 1420326 X 11421356

Zhu J, Cao X-L, Beauchamp R (2001) Determination of 2-butoxyethanol emissions from selected consumer products and its application in assessment of inhalation exposure associated with cleaning tasks. Environ Intl 26:589-597 